\title{
Pesticide Residue in Mango Orchards and Health Risk
}

\section{Tari VSS ${ }^{1 *}$, Patil PY ${ }^{1}$ and Karthik Kannan ${ }^{2}$}

${ }^{1}$ Department of Environmental Sciences, University of Mumbai, Ratnagiri

Sub-Centre, Ratnagiri, MH, India

${ }^{2}$ Center for Advanced Materials, Qatar University, Doha P.O. Box 2713, Qatar

*Corresponding Author: Tari VSS, Department of Environmental Sciences, University of Mumbai, Ratnagiri Sub-Centre, Ratnagiri, MH, India.
Received: July 06, 2020

Published: August 18, 2020

(C) All rights are reserved by Tari VSS., et al.

\section{Abstract}

The Mango (Mangifera indica) crop is commercially grown in almost all nine Taluka of Ratnagiri district. This study aims to collect baseline data regarding pesticide residue. Mango leaf samples and soil samples of mango orchard collected across Ratnagiri district to understand either the study area is under impact of pesticide pollution or not. The soil and plant materials (mango leaf) were collected from 20 different randomly selected Mango orchards. These samples were analyzed by Gas Chromatography coupled to High Resolution Mass Spectrometry (GC-HRMS) qualitative analysis for determination of pesticide residue in the mango field at the Ratnagiri district, Maharashtra, India. The extraction of soil samples is carried out by Solid-liquid partition method followed by concentration using Kuderna-Danish concentrator apparatus. Extraction of plant material carried out by Soxhlet method. Electron impact ionization (EI with $70 \mathrm{eV}$ ionization energy) mode is used during analysis. Present study reveals appearance of some pesticide residues in the field. Total 6 chemical pesticides residues viz. Carbendazim [Methyl-1H-benzimidazol-2-ylcarbamate], Cypermethrin [(Cyano - (3 - Phenoxyphenyl) methyl - 2) 3 - (2 - 2 - dichloroethyneyl) - 2, 2 dimethylcyclopropane - 1 - carboxylate], Hexaconezole (2 - (2, 4 - Dichlorophenyl) - 1 - (1H - 1, 2, 4 - triazol - 1 - yl) Hexan - 2 - ol), Imidacloprid (N - (1 - [(6 - chloro - 3 - pyridyl) methyl)] - 4 , 5 - dihydroimidazol - 2 - yl) nitramide), Monocrotophos [Dimethyl (E) 1 - methyl - 2 - (methyl carbamoyl)and phorate [0, 0 - Diethyl - S - [(ethylsulphanyl) methyl] phosphorodithioate] were found from 5 different groups such as Organophosphate, Pyrethroid, Neonicotinoids, Triazole and Benzimidazole. This study is significantly showing that the study area (Ratnagiri district) is under impact of pesticide pollution. There is well felt need of organic farming of mango to reduce health risk.

Keywords: Mangifera indica; Soil and Plant Material; GC-HRMS; Pesticide Residue

\section{Introduction}

Large population of the study area is significantly dependent on the Mango cultivation as source of their income. However, because of unsustainable agricultural practices environment is badly contaminated by many chemical agents. These are harmful to biotic and abiotic factors of environment, ultimately pose a health risk to human beings [1]. To increase production and profitability farmers are extensively using pesticides to kill pest by considering its sim- ple application techniques [2]. Chemical agents present in the pesticides are the main cause for deterioration of environment [2]. The chemical pesticides are major pollutant as they produce chronic and acute toxicity to the biological entities in the environment [2]. The objective of present study is to report pesticide residue from the soil and plant material from mango orchards where pesticides are sprayed frequently. Chemical pesticides and metabolites lose their identity and activity due to various physical processes such as 
degradation, sequestration, fixation etc. Hence, residence time of carbon from chemical pesticide varies accordingly [1].

Previous literature reported widespread pesticide contamination in the water, soil and air in the agricultural area where pesticides are heavily used. Runoff from agricultural field introduced many agrochemicals in the water bodies. The major contamination of surface water is due to agricultural runoff. These pollutants sometimes enter into the ground water. Ground water is major source for household use. It eventually comes in contact with humans. Pesticides are tending to be mobile in soils and also persistent. Potential of pesticide pollution in water bodies is dependent on state of atmosphere, tendency to dissolve in water, distance from source where pesticides are applied [2].

Organochlorine pesticides are persistent in the environment their rate of degradation is also less. DT50 (half degradation time) is long hence accumulated in the environment. However, organophosphates are comparatively less persistent in water, soil, food and animal feeds than organochlorine. Organophosphates can further breaks down in nontoxic metabolite. Below maximum residue levels (MRLs) of pesticides adverse effects on human are not expected $[2,3]$. Adsorption of chemical pesticides on soil is depending upon the availability of organic matter, $\mathrm{pH}$ and presence of clay minerals like silicate in the soil [3].

However, Effects of pesticide on human is dependent on type of the chemical pesticide, exposure period and overall health of person. It is assume that humans are 10 times more susceptible to toxic substance than laboratory animals. Sometime people that show healthy appearance won't get affected from toxic substances but they pass on toxic chemicals to their children in critical phases of their development. Young children are more sensitive to effects of toxic chemicals (Prevention of food adulteration Act 1954).

The present study mainly aimed with collection of baseline data regarding pesticide residue for the Ratnagiri district, Maharashtra. The assessment of chemical pesticide residue in the study area for mango plantation is not done before. This study is important academically and for policy makers and farmers to understand the impact of pesticide on mango ecology. Objectives for the present study are as follows

- Whether the study area is under impact of pesticides pollution or not.
- To study pesticide residue in soil samples

- To study pesticide residue in plant material.

Samples of soil and plant material from study area were qualitatively analyzed for pesticide residue by using Gas chromatography high resolution mass spectrometry (GC-HRMS) technique.

\section{Methodology}

Sampling

Total 40 samples were analyzed for pesticide residue of Cypermethrin, Quinalphos, Hexaconezole, Imidacloprid, Monocrotophos, Phorate, Carbendazim, Chloropyriphos. Out of which 20 are soil samples and 20 plant material samples. All samples were randomly collected from total 20 mango orchards across the study area, Ratnagiri District, Maharashtra, India. Soil samples were collected by using quadrate method. All samples were collected after four days of last spray.

\section{Sample reservation}

Since collection of samples to extraction; collected samples are kept in refrigerator at $4^{\circ} \mathrm{C}$ to prevent it from thermo degradation and kept in dark to avoid photo degradation from time of collection till extraction. According to standard procedure sample must be extracted within fourteen days from collection where as extracted samples can be stored at $4^{\circ} \mathrm{C}$ for a month [4].

\section{Extraction of plant material}

The plant samples were extracted by using Soxhlet extraction method with Petroleum ether as a solvent. Leaves collected from field are washed under running tap water to clean dust from the surface. Cleaned leaves weighed exactly $5 \mathrm{gm}$ and transferred to thimble. Sample covered with cotton ball to avoid spilling of sample. Pour $80 \mathrm{~mL}$ petroleum ether and adjusted temperature to $100^{\circ} \mathrm{C}$, allow the sample for soxhlation till extract volume obtained should be $5 \mathrm{~mL}$. Extracted samples kept in refrigerator till analysis.

\section{Extraction of soil samples}

The top soil is collected from the study area. Soil sample used for extraction is $30 \mathrm{gm}$. Soil samples are extracted by using solid liquid partition method by using Dichloromethane (DCM) as organic solvent followed by concentration with Kuderna Danish concentrator apparatus. Extracted sample concentrated to $5 \mathrm{~mL}$. Transferred it to vial and kept at $4^{\circ} \mathrm{C}$ till the analysis. 


\section{GC-HRMS analysis}

Extracted samples were further analyzed through Gas Chromatography - High resolution mass spectrometry (GC-HRMS) for the determination of pesticide residue. GC-MS analysis were carried out with Agilent 7890 coupled with JeolAccuTOF GCV mass spectrometer. The gas chromatograph is equipped with a column HP$5 \mathrm{MS}$ (Film thickness is $4 \mu \mathrm{m}$ ). The temperature program was $80^{\circ} \mathrm{C}$ $(1 \mathrm{~min}) / / \mathrm{ramp} 8{ }^{\circ} \mathrm{C} / \mathrm{min} / / 200^{\circ} \mathrm{C}(3 \mathrm{~min}) / / \mathrm{ramp} 10^{\circ} \mathrm{C} / \mathrm{min} / / 270^{\circ} \mathrm{C}$ $(3 \mathrm{~min}) / / \mathrm{ramp} 10^{\circ} \mathrm{C} / \mathrm{min} / / 280^{\circ} \mathrm{C}$ (final temperature). Helium (>99.999\%) gas was used as a carrier gas with flow rate $1 \mathrm{~mL} /$ min and electron ionization with $70 \mathrm{eV}$. Chromatograms obtained within mass range of 10-2000 amu with mass resolution of 6000 . The volume of sample injected during analysis was $2 \mu \mathrm{L}$. Analysis carried out at Sophisticated Analytical Instrumental Facility (SAIF) at IIT Bombay laboratory. GC-MS spectra indentified on the basis of online Restek's line of reference standard (ISO 9001:17025 Guide 34), available spectra from the NIST/EPA/NIH library [5] and online literature $[6,7]$.

During this study electron ionization mode is used. Each Gas Chromatograph peak is characterised by Mass spectra detected during analysis. In the present study chemical pesticide residue of Cypermethrin, Carbendazim, Hexaconezole, Imidacloprid, Monocrotophos and phorate are found. Mass spectra obtained from SAIF IITB are matched with published literature for validation viz. Hexaconezole [8], Imidacloprid [9] Monocrotophos, Carbendazim [10] Phorate and Cypermethrin [6]. GC-MS spectra also identified on the basis of online Restek's line of reference standard (ISO 9001:17025 Guide 34) and available spectra from the NIST/EPA/ NIH library http://webbook.nist.gov/chemistry.

\section{Results}

Various unsustainable practices adopted by farmers in the study area such as overuse of chemical insecticides, lack of manual orchard management practices (pruning, ploughing, uprooting of unwanted herbs), use of herbicide, overuse of chemical fertilizers, overuse of cultar, Fly ash (Thermal power plant) based fertilizers are revealed from cursory field survey. Raw fly ash mainly obtained from thermal power plant containing heavy metal like mercury in the soil [11]. It is observed that pest is the major problem at the study area. Primary data of consumption of chemical pesticide obtained from field showing wide use of chemical pesticide. Out of 20 mango growers across Ratnagiri district only two farmers are practicing organic method of farming. However, majority of farmers are using chemical pesticide to control mango pest. Whereas, some farmers are using chemical as well as biopesticides in more or less amount. Around $5-10 \%$ of applied amount of pesticides reaches the target pest species remaining $90 \%$ of chemical pesticides come in contact with soil and hence soil is getting polluted. It adversely affects soil flora and fauna [3]. Previous reports showed pesticide residue in plant material samples after three days of spraying which found above MRLs.

\section{Pesticides in soil samples}

Total 20 orchards were sampled across Ratnagiri district out of which 6 orchards are found to be contaminated with 6 chemical pesticides.

Hexaconezole (2 - (2, 4 - Dichlorophenyl $)$ - 1 - (1H - 1, 2, 4 - triazol - 1 - yl) Hexan - 2 - ol) from triazole groupand Imidacloprid (N-(1-[(6 - chloro - 3-pyridyl) methyl)] - 4, 5 - dihydroimidazol - 2 - yl) nitramide) from Neonicotinoid group found in soil sample of organic farmer (Figure 1). It is not expected to be present in sample because this orchard is not directly sprayed with any chemical pesticide. However, neighboring farmers are using Hexaconazole and Imidacloprid based chemical pesticides for their orchards. The appearance of these chemicals in the selected orchard is due to adjacent spraying of chemical pesticide. The entry of chemical pesticides during and after application, pollutant enters into atmosphere through drift and evaporation. Hence, transport and deposition of pesticides takes place in adjacent areas of treated orchard [12]. All other chemical pesticides are obtained in the orchard where more or less chemical pesticides are used.

Pesticides in plant materials

Carbendazim(Methyl-1H-benzimidazol-2-ylcarbamate) is Benzimidazole based pesticide detected in two samples out of twenty mango leaf samples (Figure).

\section{Discussion}

Cypermethrin [(Cyano-(3-Phenoxyphenyl) methyl-2) 3 - (2 - 2 - dichloroethyneyl) - 2, 2 dimethylcyclopropane - 1 - carboxylate] from Pyrethroids (Figure 1) is not persistent pesticide in the environment, but its indiscriminate use leads to many health risks as it is neurotoxic in nature [13]. Cypermethrin accumulation in the water bodies is mainly due to agricultural runoff which ultimately affects non target species [13]. Residue accumulation in vegetables, 

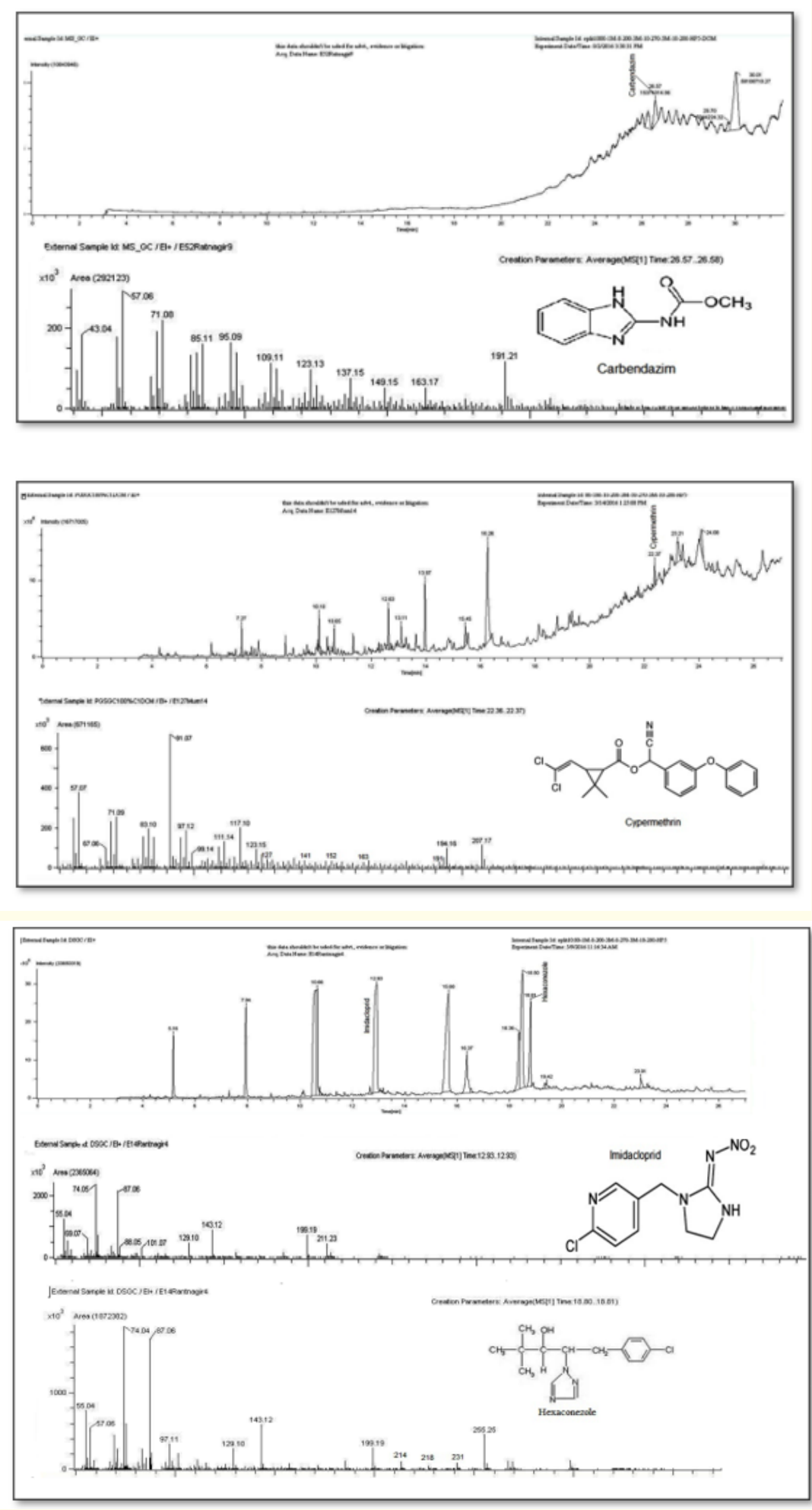

Citation: Tari VSS., et al. "Pesticide Residue in Mango Orchards and Health Risk". Acta Scientific Microbiology 3.9 (2020): 08-14. 


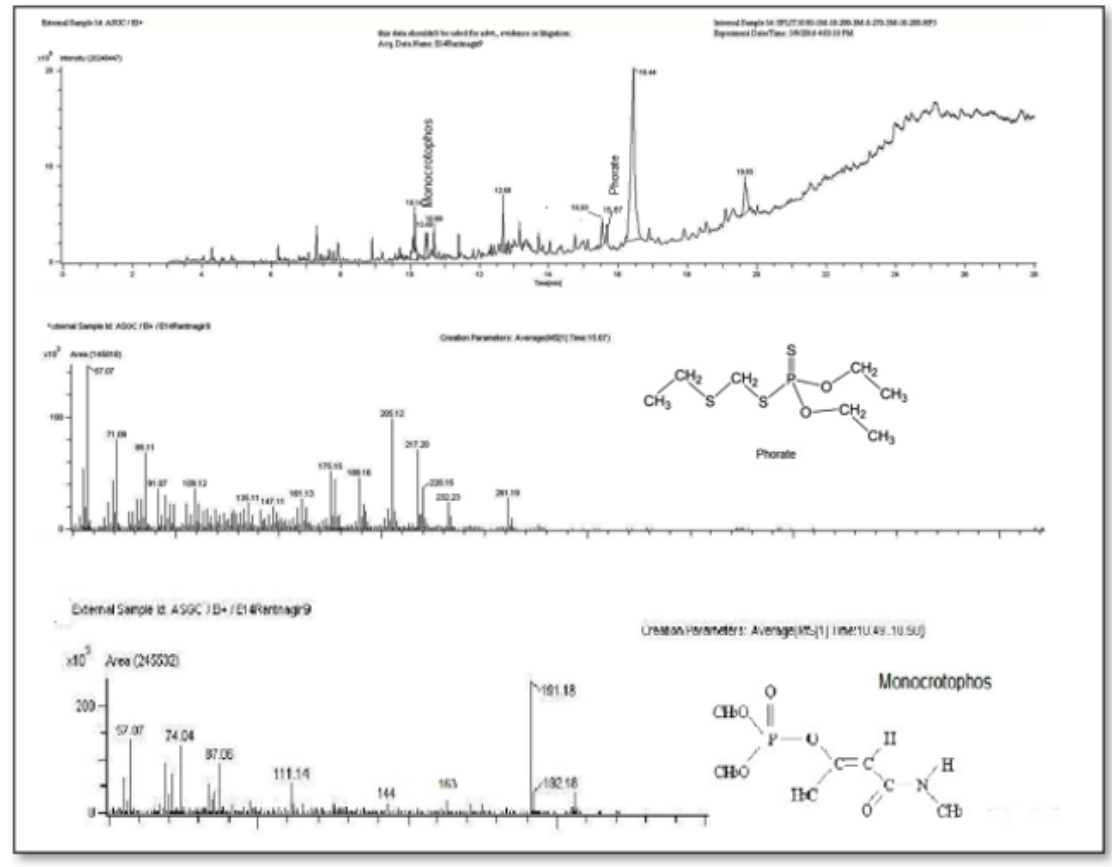

Figure 1: Pesticides Found in Soil Samples.

leaves, soil, fruits and in animal bodies reported by several studies [13].

Several studies have reported the residue of Imidacloprid (N[1-(6 - chloro - 3-pyridylmethyl)] - 4, 5 - dihydroimidazol- 2 - yl - nitramide) from various environmental samples [14]. Residue level found in pollen, nector were below the limit of quantization (LOQ 0.005 and $0.01 \mathrm{mg} / \mathrm{Kg}$ ) but youngest leaves showed residue level above the limit of quantization [14]. Residue in soil samples ranges from 0.8-2.3 ppm [15]. The time required to dissipate $50 \%$ of applied Imidacloprid is from 80 days to two years. Hence Pest Management Regulatory Agency (PMRA) classified it as a persistent pesticide in soil $[15,16]$. USEPA classified it as both Class II and III and should label as "Warning" [16]. About $110-120 \%$ of Imidacloprid concentration increases in year 1999 as compared to 1998 [16]. Biodegradation of Imidacloprid by isolated soil micro organism (Leifsonia strain PC-21) producing 6-chloronicotinic acid and Imidazolidin [3].

Carbendazim (Methyl-1H - benzimidazol - 2-ylcarbamate) from Benzimidazole (Figure 1) group residues reported in soil
[10]. It is used generally to cure fungal diseases. Toxicity of Carbendazim is studied and it is proved to be harmful for human being also has a potential to cause birth defects and male permanent infertility along with genotoxicity, testicular toxicity and neurotoxicity. According to Australian pesticide and veterinary medicine authority report half life period of Carbendazim is up to 6 months moreover, acceptable daily intake is $0.03 \mathrm{ppm} /$ day and water quality standard for drinking water is $0.09 \mathrm{ppm}$. Hence, Carbendazim has tends to accumulate in the environment [17].

Monocrotophos [Dimethyl (E) 1 - methyl - 2 - (methyl carbamoyl) vinyl phosphate] from organophosphate group of pesticides. It was found in 2 samples out of 20 soil samples. In the present study Monocrotophos and Phorate both together found in one of soil samples (Figure 1). Combination of Monocrotophos with other chemicals shows inhibition of phosphate activity. Monocrotophos is used on large scale in the Asian countries; among these India consume 43\%. Monocrotophos observed in animal tissues, human tissues, soil and plant material [18]. Monocrotophos is well reported for its toxicity in terms of histopathological, genetic, hypergly- 
caemic, neurotoxic and cardiotoxicity. It is also persistent in the environment. Half life of Monocrotophos at $25^{\circ} \mathrm{C}$ in acidic $\mathrm{pH} 3$ is 131 days and in basic pH 9 it is 26 days [18].

Phorate [0,0 - Diethyl - S-[(ethylsulphanyl)methyl] phosphorodithioate] is organophosphate insecticide widely used to control mango pest. It is effective against chewing and sucking type of pest. Half life of Phorate is 9-126 days bioaccumulation data is not available for organophosphate pesticide like Phorate [19]. Toxicity is related to histopathological deformities, degeneration of cardiac myofiber, renal necrosis, and decrease activity of antioxidative enzyme, lipid peroxidation, cellular toxicity and generic alteration [20].

Hexaconezole (2 - (2, 4 - Dichlorophenyl) - 1 - (1H-1, 2, 4 triazol -1- yl) Hexan- 2 - ol) and Monocrotophos (Dimethyl (E)1- methyl-2-(methyl carbamoyl) vinyl phosphate) is repeatedly found in 2 soil samples.

However, the presence of pesticide residue in the soil samples and plant materials is major environmental concern.

\section{Conclusion}

The chemical pesticides found at the study area are from five different groups such as organophosphate, Pyrethroid, Neonicotinoid, Triazole and Benzimidazole. This study strongly proved that the study area is under impact of pesticide pollution. The data acquired are helpful to the farmers and policymakers to understand the pollution level. There is need of organic farming to minimize chemical pesticides burden for sustainable mango production. It is also useful for the protection of consumer health from deleterious impact of pesticides.

\section{Funding}

No funding.

\section{Conflict of Interest}

None.

\section{Bibliography}

1. Joel R Coats and Hiroki Yamamoto. "Environmental fate and effects of pesticides. Chapter 1- The lysimeter concept: A comprehensive approach to study the environmental behaviour of pesticides in agro ecosystem". (2003): 1-30.
2. HB Mathur., et al. Analysis of pesticide residue in bottled water (Delhi region), Centre for science and environment (CSE) report on pesticide residues in bottled water, CSE/PML-612002 (2003).

3. Jennifer C Anhalt., et al. "Biodegradation of imidacloprid by an isolated soil microorganism". Journal of Environmental Sciences and Health Part B 42 (2017): 509-514.

4. Derek Muir Ed Sverko. "Analytical methods for PCBs and organochlorine pesticides in environmental monitoring and surveillance: A critical appraisal". Analytical and Bioanalytical Chemistry 386 (2006): 769-789.

5. http://webbook.nist.gov/chemistry

6. Howard Keith Crosby and Ron Honnald. Analysis of Cypermethrin in blueberries by Agilent 240 ion trap GC/MS^3, 1-18 (C) Agilent techs PAC (C) 5991-37733EW (2013).

7. Zheng Wei., et al. "Photochemistry of insecticides Imidacloprid: Direct and sensitized photolysis in aquatic medium". Journal of Environmental Sciences 16.4 (2004): 539-542.

8. Zhubo Deng., et al. "Simulteneous analysis of Hexaconezole, Myclobutanil and Tebuconezole residues in apples and soil by SPE clean up and GC with nitrogen-phosphorus detection". Chromatographia 71.7 (2010): 679-684.

9. SéverineSuchail., et al. "Discrepancy between acute and chronic toxicity induced by Imidacloprid and its metabolites in Apismellifera". Environmental Toxicology and Chemistry 20.11 (2011): 2482-2486.

10. Filipe F Donato., et al. "Development of a multiresidue method for pesticide analysis in drinking water by solid phase extraction and determination by gas liquid chromatography with triple quadrupole tandem". Journal of the Brazilian Chemical Society 26.10 (2015): 2077-2087.

11. Chanchal Verma., et al. "Heavy metal contamination of ground water is due to fly ash of coal fired thermal power plant, Parichha, Jhansi India". Cogent Engineering (2017): 1-8.

12. Pim EG Leonards., et al. "Advanced GC MS and LC-MS tools for structure elucidation in effect-directed analysis". W. Brack (ed.), Effect-Directed analysis of complex environmental contamination, HdbEnvChem (2011): 15. 
13. Liu Zheng Hongguo and Yu Chongtian. "Determination of pesticide residues in drinking water using automated solid phase extraction and gas chromatography with nitrogen phosphorus detection". (2014): 1-6.

14. Quaiser Saquib., et al. "Phorate induced oxidative stress, DNA damage and transcriptional activation of P53 and Caspase genes in male wistar rats". Toxicology and Applied Pharmacology (2012).

15. RS Sreenivasan., et al. "Bioaccumulation study on the Cypermethrin toxicity in fresh water field crab, Spiralothephusahydrodroma (Herst)". Journal of chemical and pharmaceutical Research JCPRCS 3.3 (2011): 397-402.

16. Ayman Daraghmeh., et al. "Imidacloprid residues in fruits, vegetables and water samples from Palestine". Environmental Geochemistry and Health (2007): 1-13.

17. Australian pesticide and veterinary medicine Authority, Australia. Human health risk assessment, Australia. Office of chemical safety and environmentally health protection (2012).

18. Vicente Andreu and Yolanda Pico. "Determination of pesticides and their degradation products in soil: critical review and comparison of methods". Trends in Analytical Chemistry 23.10-11 (2004): 772-789.

19. Michael A Kamrin. "Pesticide profile: toxicity, environmental impacts and fate". Lewis publishers, New York (1997).

20. PMEP Report. Movement of pesticides in the environment. Extension toxicology network. USDA/Extension service/National agricultural pesticide impact assessment program (1993).

\section{Assets from publication with us}

- Prompt Acknowledgement after receiving the article

- Thorough Double blinded peer review

- Rapid Publication

- Issue of Publication Certificate

- High visibility of your Published work

Website: www.actascientific.com/

Submit Article: www.actascientific.com/submission.php

Email us: editor@actascientific.com

Contact us: +919182824667

Citation: Tari VSS., et al. "Pesticide Residue in Mango Orchards and Health Risk". Acta Scientific Microbiology 3.9 (2020): 08-14. 